\title{
Discurso, estruturas e performatividade: compreendendo o mercado legal e ilegal de agrotóxicos em Livramento-Rivera
}

\author{
Arthur Borba Colen França ${ }^{1}$ \\ ${ }^{1}$ Graduando UFRGS em Relações Internacionais/ Bolsista IC FAPERGS
}

Recebido em 01/2012. Aceito para publicação em 04/2012.

Versão online publicada em 17/11/2012 (http://seer.ufrgs.br/paraonde)

\begin{abstract}
Resumo - 0 estudo do mercado legal e ilegal de agrotóxicos, a partir da fronteira Brasil-Uruguai, com atenção especial para Santana do Livramento-Rivera, pode ser realizado compreendendo o estado como discurso, práticas estruturais estruturantes e performatividade, dentro da proposta de Kevin C. Dunn. Essa compreensão permite visualizar os atores definidores das normas nas diferentes escalas (local, regional, nacional e global), evidenciando que existem discursos divergentes sobre o que deveria ser o estado e sua atuação diante das trocas legais e ilegais de agrotóxicos, bem como posturas mais ou menos flexíveis diante dos marcos legais. Os discursos se materializam em estruturas e práticas, como aduanas, operações da Polícia Federal, planos de segurança fronteiriça e o próprio contrabando. Finalmente, procura-se compreender esses discursos e práticas como performances marcadas por posições de gênero, isto é, como ações que são reiterações das ações passadas, reafirmações que estruturam e dão significado à realidade, significando o espaço (o território e sua fronteira) a partir das normas (noções de segurança e transgressão), associadas a papéis de gênero. 0 que se busca com este texto é perceber que o estado essencializado, por vezes tido como um ator único e coeso, oculta certos aspectos do objeto em questão. Isso porque esse entendimento camufla os discursos divergentes e naturaliza práticas e estruturas que são, na verdade, produtos de discursos histórica, social e geograficamente situados.
\end{abstract}

Palavras-Chave: Fronteira. Contrabando. Livramento-Rivera. Performatividade.

\section{Introdução}

0 presente texto ${ }^{1}$ busca discutir uma possibilidade de leitura do mercado legal e ilegal de agrotóxicos entre Brasil e Uruguai, com foco em Santana do Livramento - Rivera. Essa possibilidade é apresentada por Kevin Dunn no texto "There is no such thing as the state: discourse, effect and performativity" (Dunn, 2009). O referido autor argumenta que o estado deve ser percebido através de três categorias de análise: o discurso, as estruturas-estruturantes e a performatividade. Partindo desse modelo, buscar-se-á analisar a definição das normas do comércio de agrotóxicos Brasil-Uruguai, os resultados dessas definições e as reiterações e constantes significações daí decorrentes.

Diferentes agentes atuam na definição das normas, legais ou não. A nível global, podem ser citadas a Organização Mundial da Saúde (OMS ou WHO, em inglês) e a Organização das Nações Unidas para Agricultura e Alimentação (FAO, em inglês). Regionalmente, o MERCOSUL se mostra importante na análise. No nível nacional, as legislações brasileiras e uruguaias, sendo que no caso brasileiro é preciso visualizar os agentes que, de certa forma, atuam na definição dos marcos legais. Finalmente, a localidade também é instância de definição de normas, embora a população fronteiriça por vezes flexibilize as categorias "norma" e "transgressão" (Dorfman etal., 2012).

A partir dos discursos, estruturas são geradas. Essas estruturas podem ser vistas tanto como produto quanto como produtoras de discursos e outras estruturas. Ao mesmo tempo em que derivam das definições das diversas normas e das discussões por trás dessas definições, sua simples existência acaba por gerar novos discursos, novas percepções e significações do espaço e da vida cotidiana.

Discursos e estruturas, no entanto, não esgotam a questão. Há, também, o que pode ser chamado de performatividade. Esse conceito, que surge

${ }^{1}$ Que conta com o apoio do CNPq, da FAPERGS e da PROPESQ-UFRGS e insere-se no projeto "Contrabando no Cone Sul: agentes, redes e normas" 
dos estudos de gênero, convida a significar as ações como práticas reiterais citacionais (Butler, 2003 ). É dessa forma que o espaço é ressignificado, que o limite internacional é, a todo momento, confirmado, e que o contrabando reitera e cita a postura local, flexibilizadora das categorias "legal" e "ilegal”.

A performatividade, todavia, ressignifica o espaço e a realidade de forma situada, social, histórica e geograficamente. Os discursos da norma e da segurança são performatizados, na localidade, por militares, policiais e fiscais, com suas missões, barreiras, operações, desfiles e postos de controle. Em suma, o contingente dessas ações é masculino ${ }^{2} \mathrm{e}$ verifica-se isso no campo (Dorfman et al., 2012b) , na imprensa e nos informes oficiais. A todo momento, relaciona-se norma, austeridade, seriedade, oficialidade e força a um dos gêneros. Nota-se, também, que essa performatividade propõe a existência de um outro, diametralmente oposto, o transgressor, o entrangeiro, aquele que deve ser vigiado e controlado. Da mesma forma que cria-se a binaridade masculino-feminino, cria-se a binaridade segurança-transgressão, nacional-estrangeiro.

Assim, parte-se de análises escalares para chegar a conclusões e proposições. Antes disso, no entanto, faz-se necessário alguns apontamentos sobre agrotóxicos e a caracterização do mercado desse produto no Brasil. Essa contextualização será a base para os movimentos analíticos desenvolvidos no decorrer deste artigo. Como metodologia, métodos qualitativos e quantitativos; dados generalizáveis sobre contrabando são de difícil acesso, e não há análise estatística sem interpretação e sem estar de certa forma marcada por posicionamentos dos diferentes agentes. 0 trabalho de campo e depoimentos relevantes contribuem para a produção de resultados significativos (Dorfman, Borba, Duran 2012). Além de textos téoricos, o trabalho da Dra Adriana Dorfman serve de fonte base para a discussão.

\section{Agrotóxico, defensivo agrícola, agrochemical e pesticide}

Agrotóxico é o nome usual, no Brasil, para um leque de substâncias destinadas a "defender" plantas de seus predadores naturais e da competição com outras plantas não desejadas, as "ervas daninhas". São chamados também, portanto, de defensivos agrícolas (Dorfman et al., 2012).

A escolha do termo é, por vezes, um posicionamento. Agrotóxico, agroquímico, defensivo, veneno, remédio e pesticida são utilizados para referir-se ao mesmo grupo de produtos, mas a escolha por um deles reflete os agentes produtores de discurso, que são, dentre outros: aqueles ligados a empresas produtoras de agrotóxicos e a suas associações; aqueles ligados a grupos de ecologistas, segurança alimentar e direitos do consumidor; aqueles ligados à comunidade científica; aqueles atuantes no espaço midiático; aqueles que integram os órgãos de repressão ao contrabando e aqueles que praticam o contrabando (idem).

O MERCOSUL, em suas resoluções, opta por vezes pela nomenclatura "produtos fitossanitários", por vezes por "substâncias ativas" (MERCOSUL, 1996a, MERCOSUL, 1998). A OMS define como pesticide “(...) componentes químicos que são usados para eliminar pragas, incluindo insetos, roedores, fungos e plantas indesejadas (ervas-daninhas ${ }^{3}$ )" (WHO, 2012).

A FAO define que pesticide é "qualquer substância ou mistura de substâncias com a intenção de previnir, destruir ou controlar qualquer praga, incluindo vetores de doenças humanas e animais, espécies indesejadas de plantas ou animais causadores de danos (...)" (FAO, 2003). A imprensa internacional também utiliza o termo agrochemicals (The New York Times, 2012).

\section{Mercado brasileiro de agrotóxicos}

Da mesma forma que há divergências na escolha dos termos para tratar dos agrotóxicos, também o há quanto a obtenção e interpretação dos dados. A relevância do mercado brasileiro no contexto global é incontestável, tanto em consumo quanto em produção. Se o Brasil encabeça ou não o ranking, há divergências. A Associação Nacional de Defesa Vegetal argumenta: "O Brasil é o maior mercado consumidor de defensivos agrícolas? Não. Embora o controle de pragas na agricultura tropical requeira muito maior uso de defensivos agrícolas, o consumo no Brasil é muito menor que o observado em outros países" (Andef, 2011a).

O Movimento dos Trabalhores Sem-Terra, por outro lado, afirma que "O Brasil é o maior consumidor de agrotóxicos do mundo desde 2009" (MST, 2011). A aparente controvérsia não passa de

\footnotetext{
${ }^{2}$ As noções de masculino e feminino, bem como a binaridade dos gêneros, será explorada de forma breve neste texto. Para mais, ver Butler 2003.

3"Pesticides are chemical compounds that are used to kill pests, including insects, rodents, fungi and unwanted plants (weeds)". Tradução do autor.

4"Pesticides means any substance or mixture of substances intend for preventing, destroying or controlling any pest, including vectors of human or animal disease, unwanted species of plants or animals causing harm (...)". Tradução do autor.
} 
interpretações dos dados. 0 valor aplicado por hectar e em agrotóxico no Brasil é inferior aos outros grandes produtores, em parte pelo baixo preço do agrotóxico no país. 0 volume de agrotóxico empregado no país, no entanto, é o maior do mundo, bem como a quantidade de litros utilizada dividido pela área empregada. É preciso salientar, todavia, que os brasileiros não consomem grande parte dessa produção, que é destinada à exportação (Dorfman, Borba, Duran, 2012).

Qualquer que seja a interpretação, o Brasil é um dos maiores consumidores de agrotóxicos, mercado que movimentou cerca de U\$7,2bi em 2008 no Brasil (Sampaio, 2011). Em território brasileiro, a produção é oligopolizada, assim como em escala global, dado o grande montante necessário em pesquisa e desenvolvimento a essa indústra. Lá

o setor é liderado pelas 15 empresas associadas à Associação Nacional de Defesa Vegetal (Andef). São elas: Arysta, LifeScience, Basf, Bayer, CropScience, Chemtura, Dow AgroScientes, DuPont, FMC do Brasil, Iharabras, Isagro, ISK Bioscientes, Monsanto, Nisso Brasileira, Sipcam Isagro Brasil, Sumitono Chemical e Syngenta (Andef, 2011b).

Além do Brasil, China e Índia têm se tornado mais e mais relevantes para o mercado de agrotóxicos. Houve também aumento da importância da relação Brasil-Argentina; enquanto em 2001 o Brasil importou 1352 toneladas do vizinho, em 2010 importou 33765 toneladas (Sampaio, 2011). A articulação com o MERCOSUL, portanto, é crescente.

\section{As escalas das normas e os agentes que as defi- nem}

Posições diante do processo regulatório vão refletir o posicionamento sobre qual deveria ser o aparato do estado diante deste comércio, como ele deveria atuar e se e como deve acontecer a repressão ao contrabando. Sobre agrotóxicos, há muitos documentos internacionais. A maioria, porém, objetiva regular o uso e administração dos agroquímicos na produção agrícola, tendo a saúde do consumidor final e dos próprios agricultores como preocupação imediata. Os que tratam sobre comércio dessas substâncias não são numerosos. Dentre esses últimos, dois destacam-se (Dorfman, Borba, Duran, 2012).

0 primeiro, a "Convenção de Rotterdam", específica para o comércio de pesticides de uso restrito. 0 documento chama a atenção por dois pontos. Primeiramente, define uma lista de substâncias restritas, passíveis de comércio apenas em situações específicas, o que deve ser reportado à comunidade internacional. Em segundo lugar, há a necessidade que as substâncias comercializadas estejam registras no país exportador e importador. (FAO, [1998] 2011). Brasil e Uruguai são signatários da Convenção.

O outro documento é o "Código de Conduta Internacional da Distribuição e Uso de Pesticidas" 5 . Ele atribui às indústrias de agrotóxicos, e não aos estados, a responsabilidade de zelar pela qualidade dos produtos inseridos no comércio internacional. Esses produtos devem estar dentro de diversas recomendações da FAO. As indústrias também devem se assegurar que suas filiais produzam conforme regulamentações internacionais, e devem se certificar da confiabilidade do importador (FAO, 2003). A regulação em escala global, portanto, delega responsabilidades aos estados e à indústria de agrotóxicos. Essa indústria, como será mostrado, é atuante na aplicação das normas em outras escalas.

Em relação ao contrabando, os organismos internacionais são mais enfáticos. Nos relatórios da Organização Mundial do Comércio (OMC ou WTO, em inglês), contrabando aparece juntamente a outras práticas como corrupção e lavagem de dinheiro. Essas práticas precisam ser eliminadas para a segurança dos estados, do sistema internacional e dos civis. Esta, portanto, deve ser uma preocupação sistemática das nações membras do órgão (WTO, 2003). Nos documentos das Nações Unidas, o contrabando preocupante é o de pessoas,, que também deve ser prioridade na agenda internacional (UN, 2001a; UN, 2001b). As poucas resoluções que tratam de outros contrabandos enfatizam a necessidade de combatê-los por parte dos estados. Porém, estão mais preocupadas com o a utilização do objeto contrabandeado, como drogas e armas, do que com a prática em si (UN, 2008).

A preocupação com o contrabando é pouco visível nos documentos do MERCOSUL. Há, porém uma regulamentação significativa em relação ao comércio de agrotóxicos no bloco. A resolução 48/96 determina as condições para que essas substâncias possam ser consideradas de livre circulação. São os critérios principais: que sejam produzidas no MERCOSUL; que tenham seu uso autorizado e registrado pelos Estados Partes; que as substâncias apresentem características idênticas ou extremamente similares à registrada e que a empresa produtora tenha representante legal no país de

\footnotetext{
${ }^{5} \mathrm{O}$ título original do documento é "International Code of Conduct on the Distribution and Use of Pesticides". 0 significado de pesticides para a FAO já foi explicado em passagem anterior deste texto.
} 
destino. (MERCOSUL, 1996a; Dorfman, Borba, Duran, 2012).

Regulamentações posteriores, preocupadas com a uniformidade do registro das substâncias, estabelecem a extensa lista de informações que devem ser depositadas nos órgãos responsáveis dos Estados Partes para obter o registro e a livre circulação dos produtos fitossanitários (MERCOSUL, 1996b).Outros documentos ampliaram a lista de substâncias classificadas como de livre circulação (MERCOSUL, 1996c; MERCOSUL, 1996d; MER-COSUL, 1998; Dorfman, Borba, Duran, 2012).

Os documentos do bloco que apontam sobre contrabando se limitam a citar legislações nacionais e a necessidade de diálogo e ação conjunta (MERCOSUL, 2005). No código jurídico brasileiro, contrabando é definido como "Importar ou exportar mercadoria proibida ou iludir, no todo ou em parte, o pagamento de direito ou imposto devido pela entrada, pela saída ou pelo consumo de mercadoria" (Brasil, 1940). Já legislação uruguaia define que há contrabando

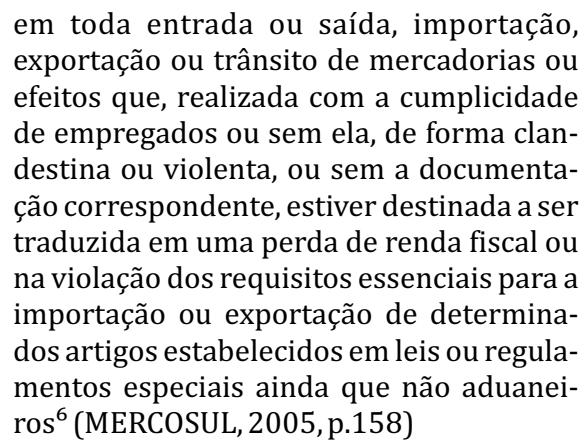

Sobre agrotóxicos, os arcabouços jurídicos também apresentam diferenciações. No Brasil, o comércio, registro ou punição por irregularidades referentes aos agroquímicos se faz pela "Lei dos Agrotóxicos". Ela determina, no artigo 13, que "a venda de agrotóxicos e afins aos usuários será feita através de receituário próprio" (Brasil, 1989). Não é permitida, portanto, a compra autônoma de qualquer agroquímico. A legislação uruguaia difere substancialmente e permite a venda de 1121 marcas comercias de agrotóxico e requer o receituário de apenas 39 delas (Uruguai, 2009). 0 Uruguai utiliza a classificação de toxicologia de agroquímicos recomendada pela OMS. O órgão agrupa os agrotóxicos em quatro categorias: Ia (produto extremamente perigoso), Ib (produto muito perigoso), II (produto moderadamente perigoso), III (produto pouco perigoso) e U (produtos que não costumam oferecer perigo) (WHO, [2010] 2009). 0 governo uruguaio requerer receituário no ato da venda apenas para os produtos classificados como Ia e Ib (Dorfman, Rekowsky 2010).

Finalmente, a escala local. Diferentemente das outras, as normas locais não costumam estar codificadas, e são tidas como costumeiras. Com costumeiro não se quer dizer uma prática recorrente pura e simplesmente, mas o costume com fonte do direito, hábitos que através da repetição e aceite sem protestos se cristalizam e adquirem caráter de norma (ICJ, 1945). Como observa Dorfman, a prática do contrabando em Santana do Livramento (Brasil) - Rivera (Uruguai):

organiza lugares e é absolutamente estrutural na sociedade fronteiriça, no abastecimento e no sustento das pessoas, sendo aí visto mais como trabalho do que como delito, realizando-se através das redes de solidariedade indispensáveis à sua execução e legitimação (Dofman 2009, 7).

Junta-se a isso argumentos como o de Foucault, que definem como criminoso "aquele que, rompendo o pacto que subscrevera, prefere seu interesse às leis que regem a sociedade de que é membro" (Foucault, [2001] 2010, p.79, ênfase adicionada). Com estes aportes, faz necessário compreender que a percepção de crime é clara, mas a prática não rompe com pacto local. É legítima, portanto. Diferentemente das outras escalas, a binaridade legal e ilegal apresenta uma zona de contato, a da legitimidade.

\section{Graus de obrigatoriedade e formas de controle}

A análise escalar feita precisa de algumas considerações. Em primeiro lugar, as normas das diferentes escalas têm abrangência, obrigatoriedade e possibilidade de sanção diferentes. As normas globais costumam ser genéricas, assumindo o formato de recomendação, e com grande espaço para interpretação. Isso se deve, geralmente, à natureza de sua construção. Estados com posicionamentos diversos precisam chegar a um denominador comum. As possibilidades de sanção e o grau de obrigatoriedade dos regulamentos globais são uma ampla discussão no Direito Internacional. Os estados, no entanto, cumprem quase todas as obrigações por eles assumidas, em quase todo o tempo.

\footnotetext{
6“en toda entrada o salida, importación, exportación o tránsito de mercaderías o efectos que realizada con la complicidad de empleados o sin ella, en forma clandestina o violenta, o sin la documentación correspondiente, esté destinada a traducirse en una pérdida de renta fiscal o en la violación de los requisitos esenciales para la importación o exportación de determinados artículos que establezcan leyes o reglamentos especiales aún no aduaneros". Tradução encontrada em Mercosul 2005.
} 
Os motivos para tal vão desde o desejo de manter a imagem de nação confiável ao fato de fazerem parte do processo de elaboração das regras e, portanto, as consideram legítimas (Amaral Jr, 2010).

No âmbito do MERCOSUL, essas características se alteram. A base institucional continua sendo o estado, mas os membros do bloco parecem descumprir as normas com mais facilidade. As resoluções aqui apresentadas, inclusive, já foram alvo de controvérsias entre Brasil e Argentina (MERCOSUL, 2002). Essa aparente flexibilização das normas existe porque não é interesse dos membros tensionarem as relações em demasia; antes unidos de forma imperfeita do que desunidos.

Os âmbitos nacional e local, no entanto, diferem-se completamente. As regulamentações globais e regionais têm como alvos os estados e suas instituições ou empresas de atuação internacional. Os códigos jurídicos nacionais e a normatividade social, por sua vez, têm como alvo os corpos e objetos. É claro que estados são formados, essencialmente, por corpos e objetos, reunidos em forma de aparatos e instituições, além do território. Lê-se essa formação, pós-modernamente, como processo-estado, ou state-making-process (Dunn, 2009). A pergunta central do presente artigo, no entanto, não é como se constrói o estado, mas como as normas, nas diferentes escalas, moldam noções de legalidade e ilegalidade, segurança e transgressão, e como essas normas associam-se a padrões de gênero.

Há de se voltar, então, para as formas de controle dos corpos e objetos pelas normas nacionais e locais. Sobre o controle dos corpos, Foucault afirma que "O poder penetrou no corpo, encontrase exposto no próprio corpo... (...). Na realidade, a impressão de que o poder vacila é falsa" (Foucault, [1979] 2011, p.146). Foucault ainda, questionado sobre quem coordena a ação dos agentes da política do corpo, afirma que "É um conjunto extremamente complexo sobre o qual somos obrigados a perguntar como ele pode ser tão sutil em sua distribuição, em seus mecanismos, seus controles recíprocos, seus ajustamentos, se não há quem tenha pensado o conjunto" (Foucault, [1979] 2011, p.151).

De fato, o controle sobre o corpo se mostra constante, mas de origem difusa. Garantir o cumprimento das leis e assegurar um ir e vir controlado é tarefa que exige uma rede de profissionais e instituições, como fiscais e órgãos como receita federal, e também tecnologias, como barreiras e câmeras de segurança. As formas de sanção são muito mais severas que as internacionais. Enquanto o descumprimento de normas globais têm o mal estar diplomático e possíveis sanções econômicas como con- sequências, o descumprimento do arcabouço jurídico nacional tem, como principal ameaça, a reclusão.

É possível argumentar, conjuntamente, que o código jurídico é cumprido porque ele é percebido como correto, de forma similar às normas internacionais. Além da ameaça de perda da liberdade, indivíduos se sujeitam a determinadas normas por entenderem que elas contribuem para o bem-estar social. Além da punição, portanto, os corpos são controlados por uma construção de moral.

As normas locais possuem funcionamento similar. Enquanto as ameaças ao descuimprimento são reais, chegando à completa inviabilidade de ser parte daquela comunidade e ser forçado a deixá-la, há uma construção de legítimo e ilegítimo. Essa construção, como anteriormente comentado, não necesseriamente equivale a legal e ilegal, e nem constituí par binário descontínuo, como nos arcabouços jurídicos. Em verdade, a continuidade legal-ilegal, através do legítimo, é tão verdadeira que o descumprimento de uma norma social, como ostentar em demasia o lucro com o contrabando, pode ser sancionado na forma de denúncia.0 alvo, assim, será envolvido em um processo legal.

Sobre o controle dos objetos, diversas instituições aparecem como mercanismos com este fim, como a Agência Nacional de Vigilância Sanitária (ANVISA), a Receita Federal, a Polícia Federal e o INMETRO. Além, novamente, de uma moralidade sobre como tratar os objetos, há a ameaça de seu confisco em caso de descumprimento, e até mesmo de reclusão.

\section{As estruturas estruturantes que emanam dos discursos}

Das normatividades e seus métodos de aplicabilidade, emanam estruturas. Dunn, quando analisando o processo de construção dos estados, definiu as estruturas como a materialidade física dos discursos, seus traços paupáveis (Dunn, 2009). Apropriando-se desse conceito, delimitam-se as estruturas como a materialidade gerada pelas definições das normas nas diferentes escalas. Essas estruturas são estruturantes porque delas próprias outras estruturas podem emanar, outros discursos podem se formar, criando novas percepções de realidade e tornando o processo de materialização contínuo. É por esse motivo que essas estruturas, por vezes, parecem naturais do arranjo social, e não em algum momento produzidas.

Diferentemente das normas, em que parece haver uma delimitação mais clara das divisões escalares, estruturas que são originadas por determinados agentes por vezes interajem e atuam sobre 
outros agentes, em outras escalas. Ademais, certos agentes parecem promover continuidade escalar, como as empresas de agrotóxico, internacionais, mas estabelecidas no Brasil com filiais de grande porte, apresentando-se à opinião pública como empresas nacionais (Dorfman, Borba, Duran, 2012).

Há, nesse sentido, estruturas que parecem emanar dos discursos normativos internacionais. Da preocupação com o contrabando e da necessidade de regular a utilização de agrotóxicos surgem, por exemplo, fóruns de negociação internacional, ONGs de atuação internacional que militam pela agricultura orgânica, operações das tropas internacionais para combater o contrabando de pessoas e eventos repercutivos, como "Rio+20". Essas estruturas têm como objetivo ou firmar e aplicar acordos para vigilância de fronteiras, portos e aeroportos ou se debruçar sobre formas de utilizar agroquímicos.

Além da criação de uma agenda internacional, as regulações globais também repercurtem nos níveis nacional e local. 0 estabelecimento de normas para o comércio de agrotóxicos e de alimentos com agrotóxicos estimula a internalização dessas normas. A ANVISA, nesse sentido, define formas de aplicação e concentrações aceitáveis de diversos agrotóxicos, como o carbendazin, utilizado na citricultura (ANVISA, 2005). Em parte, essa internalização das normas vêm da pressão do discurso internacional, mas ela também é motivada para adequar a produção nacional às exigências do mercado (Duran et al., 2012). A necessidade de combater o contrabando advogada a nível global também se manifesta em outras escalas. Os estados são recomendados a fortalecerem suas instituições de controle e repressão, e aqueles que não o fazem são acusados de negligência pela comunidade internacional.

Essas efeitos estruturais se tornam mais evidentes nas escalas locais, nacionais e do MERCOSUL. As estruturas oficiais proliferam-se. Como os códigos jurídicos estabelecem clara distinção entre o legal e o ilegal, classificando o contrabando na segunda categoria, eles levam à criação de órgãos para reprimir o ilegal, controlando os objetos e corpos. Esse controle, introduzido anteriormente neste texto, será feito pelas aduanas em cidades fronteiriças, aeroportos e portos; por instituições como a o Exército e a Marinha, a Polícia Federal, a Polícia Rodoviária Federal e a Receita Federal. Esses efeitos, no entanto, podem ser associados a um processo mais amplo, o de construção verdadeira do estado. Há, porém, efeitos mais específicos.

A Operação Ágata exemplifica o argumento. Segundo sítio do Ministério da Defesa Brasileiro
(...) a Operação Ágata, sob controle do Ministério da Defesa, possui caráter interagências e não se enquadra como uma ação típica de defesa. Trata-se de um conjunto de ações pontuais contra o crime transfronteiriço, que conta com o apoio de vários órgãos federais, sob a coordenação do Estado-Maior Conjunto das Forças Armadas (EMCFA). Além da Polícia Federal, participam da iniciativa a Agência Brasileira de Inteligência (Abin), o Instituto Brasileiro do Meio Ambiente e dos Recursos Naturais Renováveis (Ibama), o Instituto Chico Mendes (ICMBio), a Receita Federal e a Fundação Nacional do Índio (Funai), bem como as secretarias de Segurança Pública dos estados envolvidos (Ministéro da Defesa, 2012a).

Um conjunto de instituições, portanto, é mobilizado para combater o chamado crime transfronteiriço. Ainda no portal do Ministério da Defesa, encontramos o saldo da operação Ágata 5, que

resultou na prisão de 31 pessoas e apreensão de 6 toneladas de entorpecentes. Em 15 dias de ação o aparato militar recolheu 182 carros e embarcações numa área de 3,9 mil quilômetros de fronteira com Bolívia, Paraguai, Argentina e Uruguai. (...). Esta edição da Ágata mobilizou 17 mil militares da Marinha, do Exército e da Aeronáutica, além de civis (...). (Ministério da Defesa, 2012b).

Também é póssível citar o Plano Estratégico de Fronteiras, o PEF. Na ocasião de seu lançamento, em 2011, a então presidenta do Brasil, Dilma Roussef, argumenta que

Com isso nós vamos construir, em parceria
- obviamente - com os estados e municípi-
os fronteiriços, nós vamos construir uma
capacidade de ação muito efetiva do gover-
no brasileiro. E mais, eu acredito que o
Brasil e todos os países fronteiriços (...) têm
todas as condições para (...) permitir que
nós estruturemos com os nossos países
amigos uma ação coordenada (...) firme que
nos levará, de fato, a combater todas as
formas de crime organizado, que escolhe as
fronteiras como regiões mais frágeis e,
portanto, mais próprias para sua atuação. 0
que nós queremos é fortalecer as nossas
regiões de fronteira (Roussef, 2011).

Além da mobilização de várias instituições, portanto, há o ensejo de uma ação conjunta entre os governos da região para "fortalecer a nossa região de fronteira". A presença militar, por exemplo, da mesma forma que advém de uma visão sobre a securitização o espaço e controle dos fluxos, deriva percepções de segurança (Dunn, 2009). 
Dada a impossibilidade de vigiar todas as mercadorias que transitam pelo país, são estabelecidas metas em volume de apreensões de mercardorias contrabandeadas pelos órgãos de controle. No caso dos agrotóxicos, há no Brasil uma discussão que envolve sindicatos de produtores, agroecologistas e a sociedade em geral, condenando enfaticamente e demandando a repressão ao contrabando, estabelecendo assim, essa meta. De fato, o principal promotor da Campanha nacional de combate ao contrabando de agrotóxicos é o Sindicato das Indústrias Nacionais de Defensivos Agrícolas, o Sindag (Dorfman, Rekowsky, 2010).

Além disso, as campanhas transformam a percepção do contrabando. Como anteriormente dito, o contrabando é usualmente aceito como prática ilegal, mas legítima. 0 item agrotóxico, no entanto passa da indiferença à enfática condenação. As campanhas deslocam, ainda, o entendimento do risco do uso de agrotóxicos, limitando o perigo aos contrabandeados. Ao se conversar fronteiriços, observa-se que a expressão agrotóxico passa a designar contrabando, enquanto o agroquímico produzido nacionalmente é chamado defensivo (Dorfman, Borba, Duran, 2012).

Dessa forma, privados pressionam instituições públicas a reforçarem os discursos normativos, organizando-se em campanhas que envolvem material midiático e capacitação de locais e de agentes do estado, sendo esta, portanto, uma prática realmente estruturante. Nota-se que que há um entroncamento de responsabilidades, fato que pode ser visto como interação das normatividades das diferentes esclas. Além do Sindag, o já citado MST têm seu posicionamento diante do uso de agrotóxicos, organiza a campanha "Agrotóxico Mata!" e pressiona os legisladores e fiscalizadores a agirem.

É preciso analisar, enfim, as estruturas geradas pela população de Livramento-Rivera. Em primeiro lugar, o próprio contrabando deve ser visto como prática estruturante, já que resulta da aceitação local. Como viável, o contrabando acaba por formar uma rede de confiança, estruturando parte da sociedade (Dorfman, 2009).

O contrabando de agrotóxicos exige uma profissionalização dos agentes. Devido aos grandes volumes contrabandeados e os destinos, por vezes o Centro-Oeste do Brasil, a percepção do contrabando de agrotóxicos é diferente daquela do pequeno contrabandista. Dada a diferença de legislação, é legal a venda de defensivos em Rivera sem receita, mas ilegal sua entrada em Livramento. Junto à comunidade, assim, sentem-se os efeitos das intensas campanhas movidas pelos produtores de agrotóxicos, criminalizando o contrabando, estimulando a repressão pelos órgãos policiais.
Como envolve civis que extrapolam os limites locais, o contrabando de agrotóxicos também acaba por dar origem a uma rede complexa e multiescalar de relações, criando uma separação entre os transportadores de agrotóxico contrabandeado e a população local (Dorfman et al., 2012).

\section{A performatividade}

Após analisar os discursos normativos e as estruturas geradas a partir deles e da interação de diferentes agentes por eles guiados, faz-se necessário discutir como essas estruturas, em seu processo de funcionamento, acabam por se associar e reforçar padrões de gênero. Os estudos de gênero vêm sistematicamente demonstrando que o processo de delimtação do sexo binário vai além da biologia e está relacionado à cultura. Metáforas, como a de um porta-casacos que recebe diferentes vestes como o sexo que pode ter diferentes gêneros (Scott, 1990), foram utilizadas para tentar explicitar esse processo. É em "Problemas de Gênero", porém, que a binaridade macho-fêmea é revista. Butler argumenta que

o gênero não é um substantivo, mas tam-
pouco é um conjunto de atributos flutuan-
tes, pois vimos que seu efeito substantivo é
performativamente produzido e imposto
pelas práticas reguladoras da coerência de
gênero.(...). Nesse sentido, o gênero é sem-
pre um feito, ainda que não seja obra de um
sujeito tido como preexistente à obra. (...)
não há "ser" por trás do fazer, do realizar e
do tornar-se; o "fazedor" é uma mera fic-
çãoo acrescentada à obra - a obra é tudo.
(...) não há identidade de gênero por trás
das expressões do gênero; essa identidade
é performativamente constituída, pelas
próprias "expressões" tidas como seus
resultados (Butler, 2003, p.48, ênfase no
original)

Butler, no fragmento acima, explicita que o gênero é performativamente contruído. A performatividade difere da simples performance, de um simples ato, porque é reiterativa e citacional $(\mathrm{Bu}-$ tler, 2003). Isso significa que as estruturas-estruturantes, derivadas de discursos, são mantidas por pessoas. Essas pessoas, quando agem, não o fazem de modo anacrônico. Seus atos possuem significado, em grande parte, porque são uma repetição de eventos passados, uma confirmação de que essa estrutura continua relevante, reiterando sua existência. Esse acontecimento é citacional a porque recupera o núcleo da estrutura e o discurso que a compõe.

Durante a Operação Ágata, por exemplo, os homens das Forças Armadas provavelmente mar- 
chavam disciplinadamente, e avançavam pelo território com seus veículos e armas em riste. Essa performance têm o significado que têm porque retoma todos aqueles que já marcharam e atiraram. Esses homens estão, na verdade, citando todas as perfomances anteriores, e é por isso que seus atos têm esse significado. Se vestir de militar, andar como um militar e portar armas como um militar torna um homem um militar porque todas essas perfomances são citações das outras. É nesse sentido que Butler argumenta que "não há 'ser' por trás do fazer". Um militar é um militar porque ele age como um, ou performa como um,da mesma forma que um homem é um homem não porque ele possui um pênis ou o cariótipo XY, mas porque ele age como um, constrindo sua masculindade performativamente.

A performatividade poderia ser analisada de formas diversas. Operações oficiais, por exemplo, ressignificam o espaço e aparentam confirmar que o limite internacional é uma mudança de paradigma. Homens com uniformes diferentes, armas diferentes e carros diferentes reforçam a percepção de que "do outro lado" da fronteira há realmente "outro". A linha-líñea, com é chamado em Livramento-Rivera o limite internacional, também é significada através do contrabando. 0 ato de cruzar e recruzar o limite ajuda a delimitar a fronteira como local de passagem, e não local que deveria estanque como sugerem as operações dos órgãos de repressão.0 ponto que este texto gostaria de chamar a atenção é como a performatividade das estruturas de controle se associa e reforça padrões degênero.

Como visto, as normas globais, regionais e nacionais constroem uma binaridade descontínua entre o legal e o ilegal, diferentemente da normatividade local. Também há a construção de uma binaridade descontínua entre masculino e feminino. 0 que acontece, portanto, é que a mesma performatividade que informa sobre segurança e ordem também informa sobre masculinidade. A dinâmica das ações das forças armadas e outras instituições, performance ligada às estruturas geradas a patir dos discursos normativos, são feitas majoritariamente por homens. Homens não pela sua genitália, já que esta não é mostrada, e sim pressuposta, mas homens pelo seu agir.

A performance do controle também informa sobre quem está sendo controlado. 0 uniforme, por exemplo, diferencia quem reprime de quem é reprimido, associando ordem ao primeiro e desordem ao segundo. As fotos de apreensões da Polícia Federal remetem também a uma plasticidade da ordem, enfileirando munições e valores perfeitamente, regrando os objetos antes dispersos. Se há uma descontinuidade entre o legal e o ilegal para esses órgãos, e o legal é representado por essa estética da regra, cabe ao ilegal a desordem e a necessidade de controle. A figura do contrabandista, assim, é localmente vista mais como profissão do que crime, mas para os policias não imersos na comunidade, alguém que deve ser monitorado. Uma escala aceita zona intermediária entre regra e delito, outra não.

Além disso, se a masculinidade e a ordem são performadas conjuntamente, o que resta à transgressão? Mesmo que majoritariamente não sejam publicados o registro visual dos contrabandistas ou das apreensões realmente volumosas, elas estão implicitamente conectadas ao feminino, ou, pelo menos, a uma outra masculinidade. Isso apenas porque as duas descontinuidades, legalilegal masculino-feminino, são percebidas e associadas através da performatividade. Se os pares não fossem necessariamente binários e descontínuos, essa associação talvez não seria feita.

Não se deve, porém, crer que essa associação é tão direta quanto esta argumentação pode sugerir. Este movimento é muito mais uma ferramenta de análise do que um correspondente direto da realidade. 0 ponto é a consequência desta associação. Mais do que segurança ser associada ao masculino, o masculino é associado à segurança. $\mathrm{A}$ performatividade das estruturas repressivas, assim, reforça noções tradicionais dos padrões de gênero, contribuindo para sua perpetuação na escala local. É desta maneira que os discursos normativos sobre contrabando e agrotóxico, das diferentes escalas, derivam estruturas que auxiliam no processo de delimitação e manutenção dos papéis de gênero.

\section{Considerações finais}

Encerra-se, assim, a análise proposta pelo presente texto. 0 movimento teórico ensaiado foi o de retomar a formação das normas do comércio de agrotóxico e contrabando nas diferentes escalas. 0 global, regional, nacional e local normatizam de forma diferente os dois tópicos. Em seguida, tentou-se demonstrar que estruturas estruturantes se originam a partir dessas normatividades, estruturas essas que não devem ser tidas como naturais e dadas, e nem o estado essencializado e coeso. Finalmente, analisa-se a performatividade, o funcionamento dessas estruturas, e percebe-se como ela, além de contruir pares de legal-ilegal, normatrangressão, nacional-estrangeiro, associa esses pares a outra binaridade que é socialmente construída como descontínua, a masculino-feminino. 


\section{Referências}

Amaral Jr, Alberto do. Introdução ao Direito Internacional Público. São Paulo: Atlas, 2010.

Andef. “ 0 que é importante saber sobre defensivos agrícolas". Acesso em 14 de Dezembro de 2011a.. Disponível em http://tinyurl.com/bwg3jeq.

Andef. “A Instituição”. Acesso em 14 de Junho de 2011b. Disponível em http:// www.andef.com.br/conheca/.

ANVISA. Consulta Pública n 09, de 11 de março de 2005. Brasília: Diário Oficial da União, 2005. .

Brasil. Decreto-Lei n 2848, de 7 de dezembro de 1940: Código Penal. Brasília: Diário Oficial da União, 1940. .

Brasil. Lei n. 7.802/89, de 11 de julho de 1989. Sobre agrotóxicos, seus componentes e afins. Brasília: Diário Oficial da União, 1989.

Butler, Judith. Problemas de gênero: feminismo e subversão de identidade. Traduzido por Renato Aguiar. Rio de Janeiro: Civilização Brasileira, 2003. .

Dorfman, Adriana. "Contrabandistas na frontiera gaúcha: escalas geográficas e representações textuais". Tese de Doutorado, UFSC, 2009 . .

Dorfman, Adriana; Borba, Arthur; Duran, Roberta C."Ordem Normativa e Contrabando no Mercado Brasileiro de Agrotóxicos. Trabalho apresentado no XVII Encontro Nacional de Geografia, Belo Horizonte, Julho 22-28, 2012 .

Dorfman, Adriana; Borba, Arthur; Duran, Roberta; Soares, Guilherme."Contrabando e Mercado Legal-ilegal de agrotóxicos: articulações a partir da fronteira Brasil:Uruguai". Texto a ser apresentado no IV Seminário América Platina, 2012.

Dorfman, Adriana; Soares, Guilherme; Borba, Arthur; Duran, Roberta. "Estratégias Espaciais dos Fiscais Municipais em Santana do Livramento (RS)". Trabalho apresentado na 28a Reunião Brasileira de Antropologia, São Paulo, Julho 2-5, 2012b. .

Dorfman, Adriana; Rekowsky, Carmen. "Geografia do contrabando de agrotóxico na fronteira gaúcha". Revista Geográfica da América Central, v. 1, Heredia, 2010 . .

Dunn, Kevin. "There is no such thing as the state: discourse, effect and performativity". Texto apresentado na FAU Conference 2009, Copenhagen Business School, Dinamarca, Maio 12-13, 2009.

Duran, Roberta; Dorfman, Adriana; Borba, Arthur; Soares, Guilherme. “Quem Regula o suco de Laranja?”. Trabalho apresentado no Encontro Estadual de Geografia, Rio Grande, 2012.

FAO. Rotterdam Convention. Edição 2011. Roma:
Secretaria da Convenção de Rotterdam, 1998.

FAOInternational Code of Conduct on the Distribution and Use of Pesticides. Roma: Secretaria da FAO, 2003.

Foucault, Michel. Microfísica do Poder. Edição 2011. Rio de Janeiro: Graal, 1979.

Foucault, Michel. Os anormais. 2a Edição, 2010. São Paulo: Martin Fontes, 2001.

ICJ. Estatuto da Corte Internacional de Justiça. Nova Iorque: ICJ, 1945.

MERCOSUL. Resolução 48/96. Buenos Aires: MERCOSUL, 1996a.

MERCOSUL. Res oulução 87 / 96 . Brasília: MERCOSUL,1996b.

MERCOSUL. Resolução 149/96. Fortaleza: MERCOSUL, 1996c.

MERCOSUL. Resolução 156/96 . Fortaleza: MERCOSUL, 1996d.

MERCOSUL.Resolução 71/98. Rio de Janeiro: MERCOSUL, 1998.

MERCOSUL. Controversia entre la República Argentina y la República Federativa del Brasil sobre 'Obstaculos al ingreso de productos Fitosanitarios Argentínos em el Mercado Brasileño. MERCOSUL, 2002.

MERCOSUL. Primeiro relatório sobre a aplicação do direito do MERCOSUL pelos tribunais nacionais (2003). Montevidéu: Konrad, 2005.

Ministério da Defesa. "Operações em andamento". Acesso em 20 de Julho de 2012a. . http://tinyurl.com/dxl8cel Ministério da Defesa. "Ágata 5 termina com 31 pessoas presas e 6 toneladas de drogas apreendidas". Acesso em 20 de Julho de. 2012b.. http://tinyurl.com/bwfen9h

MST.“Campanha contra o uso de agrotóxicos”. Acesso em 4 de Janeiro de 2011. http://www.mst.org.br /Campanha-contra-o-uso-de-agrotoxicos.

Roussef, Dilma.“Discurso da Presidenta da República, Dilma Roussef, na cerimônia de lançamento do Plano Estratégico de Fronteiras". Palácio do Planalto, 08 de Junho de 2011.

Sampaio, Ivan Amâncio.“O mercado brasileiro de defensivos agrícolas: principais países fornecedores" Acesso em 30 de Outubro de 2011. . http:// grupocultivar.com.br.

Scott, Joan W. Gênero: uma categoria útil de análise histórica. Educação e Realidade 16(2) 5-22, 1990. 
The New York Times."Bayer to Buy Agrochemicals Unit of Aventis". Acesso em 29 de Agosto de. 2012. http:// tinyurl.com/d5qp6pl

UN. GA/SHC/3633. Press Release, 2001a.

UN.GA/SHC/3689. Press Release, 2001b.

UN. SC/9352. Nova Iorque: Department of Public Information, 2008.

Uruguai. Decreto n 482/009 del 19 de octubre de 2009.
Montevideo: Uruguay, 2009.

WHO. The WHO Recommended Classification of Pesticides by Hazard. Edição 2010. Roma: Secretaria da WHO, 2009.

WHO. "Pesticides". Acesso em 20 Julho de 2012. http://www.who.int/topics/pesticides/en/.

WTO. Trade Policy Review: Bulgaria. 2003. Acesso em 30 de Agosto de 2012. http://tinyurl.com/969zm6j

\title{
Discourses, structures and performativity: understanding the legal and illegal market of pesticides in Livramento-Rivera.
}

\begin{abstract}
The study of the legal and illegal market of pesticides from the Brazil-Uruguay border, with special attention to Santana do Livramento-Rivera, can be done understanding the state as discourse, structural and structural practices and performativity, within the proposal of Kevin C. Dunn. This understanding allows visualizing the actors that define the norms in different scales (local, regional, national and global), showing that there are divergent discourses on what should be the state and its actions in the face of legal and illegal trade of pesticides and postures more or less flexible in the face of legal frameworks. Discourses materialize in structures and practices, such as Customs, Federal Police operations, plans for border security and smuggling itself. Finally, we seek to understand how these discourses and performances are marked by gender positions, ie as actions that are reiterations of past actions, reaffirmations that structure and give meaning to reality, meaning space (territory and its border) from norms (notions of safety and transgression), associated with gender roles. What is sought in this paper is to realize that the state essentialized, sometimes taken as a single cohesive actor, hide aspects of the object in question. That's because this understanding conceals the divergent discourses and naturalizes practices and structures that are actually products of historical discourses, socially and geographically situated.
\end{abstract}

Keywords: Borders. Smuggling. Livramento-Rivera. Performativity.

\section{Discursos, estructuras y performatividad: comprender el mercado legal e ilegal de pesticidas en Livramento-Rivera.}

Resúmen - El estudio del mercado legal e ilegal de pesticidas desde la frontera entre Brasil y Uruguay, con especial atención a Santana do Livramento-Rivera, se puede hacer compreendendo el Estado como discurso, estructuras y prácticas estructurales y y la performatividad, dentro de la propuesta de Kevin C. Dunn. Esta comprensión permite la visualización de los actores que definen las normas en diferentes escalas (local, regional, nacional y global), mostrando que hay discursos divergentes sobre cuál debe ser el Estado y sus acciones delante del comercio legal e ilegal de pesticidas y posturas más o menos flexible delante de los marcos legales. Los discursos se materializan en las estructuras y prácticas, como las aduanas, operaciones de la Policía Federal, los planes para la seguridad fronteriza y el contrabando en sí. Por último, tratamos de entender cómo estos discursos y actuaciones están marcadas por las posiciones de género, es decir, como acciones que sean reiteraciones de las acciones pasadas, reafirmaciones que estructuran y dan sentido a la realidad, es decir, el espacio (territorio y sus fronteras) de las normas (las nociones de seguridad y la transgresión), asociado con los papeles de género. Lo que se busca en este trabajo es darse cuenta de que el estado esencializada, a veces se toma como un actor coherente único, oculta los aspectos del objeto en cuestión. Eso es porque esta comprensión encubre los discursos divergentes y naturaliza las prácticas y estructuras que son en realidad productos de discursos históricos, social y geográficamente situados.

Palabras-Llabe: Frontera. Contrabando. Livramento-Rivera. Performatividad. 